\title{
O SUS na lógica da descentralização
}

JOÃO YUNES

$\mathrm{N}$ A VIII CONFERÊnCia Nacional de Saúde, realizada em 1986, em plena transição democrática, foi aprovada a proposta que mudaria radicalmente a forma como vinha sendo tratada a questão da saúde no país. A proposta previa a criação do SUS e a municipalização da saúde, idéias que acabaram sendo inscritas na Constituição de 88 , com sua posterior regulamentação por meio das leis 8080 e 8142 , de 1990. "A saúde é um direito de todos e dever do Estado", diz o texto constitucional, ao adotar o modelo do Sistema Único de Saúde - o SUS -, consubstanciado em três diretrizes básicas: a descentralização, o atendimento integral e a participação da comunidade. O novo modelo, segundo se estatuiu nos diplomas legais, deve levar em conta que a questão da saúde não pode ser vista isoladamente, mas associada às políticas públicas de saneamento, moradia, alimentação, transporte, emprego e lazer.

O Inamps, criado em 1974, e que desde então passara a ser o principal órgão público de assistência médica, foi transferido do âmbito do Ministério da Previdência Social para o do Ministério da Saúde, sendo posteriormente extinto, em 1993. Com o SUS em processo de construção, a responsabilidade pela assistência à saúde da população passaria aos municípios, com recursos técnicos e financeiros a serem fornecidos pela União e pelos estados, conforme o inciso VII do artigo 30 da Constituição Federal.

Para favorecer sua implantação, o Conselho Nacional de Saúde, por proposta do Conasems (Conselho Nacional de Secretários Municipais de Saúde), oficializou por portaria em julho de 1991, a Comissão Intergestores Tripartite (CIT), que já vinha funcionando desde o ano anterior em caráter oficioso. Em 1993, os três parceiros que constituem o SUS - municípios, estados e União - deram um passo significativo para pôr de pé o novo sistema, com a aprovação da Norma Operacional Básica (NOB) 01/93. Além de normas para a descentralização e a municipalização, a NOB 01/ 93 propunha uma mudança no modelo assistencial, oficializava a CIT como instância de negociação e pactuação, e criava as Comissões Bipartites nas unidades federativas, com representantes dos gestores municipais e do gestor estadual. Tais instâncias se transformaram em fóruns de discussão suprapar- 
tidários, com a preocupação primordial de operacionalizar políticas, estudar estratégias, discutir tetos financeiros e definir com clareza os papéis e as responsabilidades dos diferentes atores.

Como resultado dessa forma solidária e consensual de agir, foi possível a habilitação, ainda em 1994, dos primeiros 24 municípios em gestão semiplena, 537 em gestão parcial, e 1.836 em gestão incipiente. Em 1995, esses números foram, respectivamente, 56, 612 e 2.131; em 1996, 137, 619 e 2.369 .

Durante a $10^{\text {a }}$ Conferência Nacional de Saúde, realizada em setembro de 1996, o Diário Oficial da União publicava a NOB 01/96, fruto de um ano de pactuação na CIT e no Conselho Nacional de Saúde (CSN), com vistas a aprofundar e a ampliar os conceitos da NOB 01/93. Em 1997, a CIT voltou-se para a questão do financiamento das propostas contidas na NOB 01/96, com a criação, pela Portaria 1882, de dezembro de 97, do Piso de Atenção Básica (PAB), que modificou alguns artigos da NOB. Por sua vez, as Instruções Normativas 01/97 e 0/98 estabeleciam os critérios para a habilitação, publicadas respectivamente em maio de 97 e janeiro de 98.

Com esses novos instrumentos, aumentou consideravelmente o interesse de gestores municipais em se habilitar para uma das duas condições de gestão preconizadas - a Plena da Atenção Básica de Saúde e a Plena do Sistema Municipal de Saúde. A grande novidade, introduzida pela portaria 1882, foi a de possibilitar a descentralização, com incentivos a atividades como a de vigilância sanitária e a de carências nutricionais, assim como o estímulo ao Programa de Agentes Comunitários de Saúde (PACS) e ao Programa de Saúde da Família (PSF).

Dados de outubro de 1998 revelavam que o PACS já estava implantado em 3.339 municípios, onde operavam 82.370 agentes comunitários, enquanto o PSF já abarcava 953 municípios, com 2.616 equipes em plena atividade. Como resultado, já se obtinha uma acentuada queda na mortalidade infantil e no número de internações hospitalares.

De outra parte, no mesmo mês de outubro de 1998 o Ministério da Saúde contabilizava um total de 5.002 municípios habilitados para cumprir as diretrizes do SUS no tocante à descentralização: 449 em Gestão Plena do Sistema Municipal e 4.553 em Plena da Atenção Básica.

\section{A modernização do Estado}

Como parte da política do governo Fernando Henrique de modernização do Estado brasileiro, que se expressa, entre outros pontos, no repas- 
se de atribuições e recursos para os estados e municípios, os responsáveis pelo setor da saúde vêm dando o seu exemplo, mesmo porque a descentralização e a municipalização da saúde são uma resposta à demanda da sociedade, expressa democraticamente em quatro Conferências Nacionais de Saúde e acolhida em disposições constitucionais e leis ordinárias.

O SUS, embora susceptível a críticas pontuais, mesmo por causa da complexidade das questões a serem enfrentadas, é um sistema democrático e suprapartidário de redistribuição de poder e de recursos; de redefinição do papel dos gestores públicos (e de suas responsabilidades financeiras); de estabelecimento de relações consensuais entre os diferentes níveis de governo; e de reorganização institucional.

Ressalte-se, igualmente, a atenção dada à participação popular, por intermédio dos Conselhos de Saúde, organizados em todas as instâncias. Tais órgãos dispõem de flexibilidade para aderir ou para adaptar-se às regras do SUS, segundo as possibilidades e peculiaridades sócio-econômicas, locais e regionais. A negociação substituiu a imposição vertical, trazendo como contrapartida a atribuição de responsabilidades. Tais características se tornam ainda mais relevantes quando se tem pela frente a necessidade da organização dos fluxos de demanda e da racionalização do uso de recursos de média a alta complexidade. A atenção à saúde não pode ser atomizada; antes deve ter em vista a integralidade do atendimento e a busca da diminuição das disparidades regionais.

Por tudo isso, tornou-se imperativa a transferência de poder e de recursos da União para os estados e municípios. Contudo, diante das dimensões territoriais e das complexidades brasileiras, esse processo exigiu e continuará exigindo mudanças de várias ordens, pois é sabido que não bastam os instrumentos e as medidas legais para que uma empreitada tenha sucesso. Urge alterar não apenas os formatos institucionais, mas sobretudo as práticas de gestão, tanto nos órgãos que transferem como nos que recebem atribuições.

De outra parte, o processo de descentralização não garante, por si só, que todos os municípios realizem uma gestão eficaz. Nem todos reúnem as condições exigidas, tanto do ponto de vista da infra-estrutura disponível, como do gerenciamento e até mesmo da aceitação dos valores que permeiam uma nova prática social. No Brasil, o município é um ente federativo e, como tal, não depende de transferência de competências do estado e da União para a gestão de seu sistema de saúde, embora dependa dos recursos advindos desses níveis de governo para exercer suas funções. 


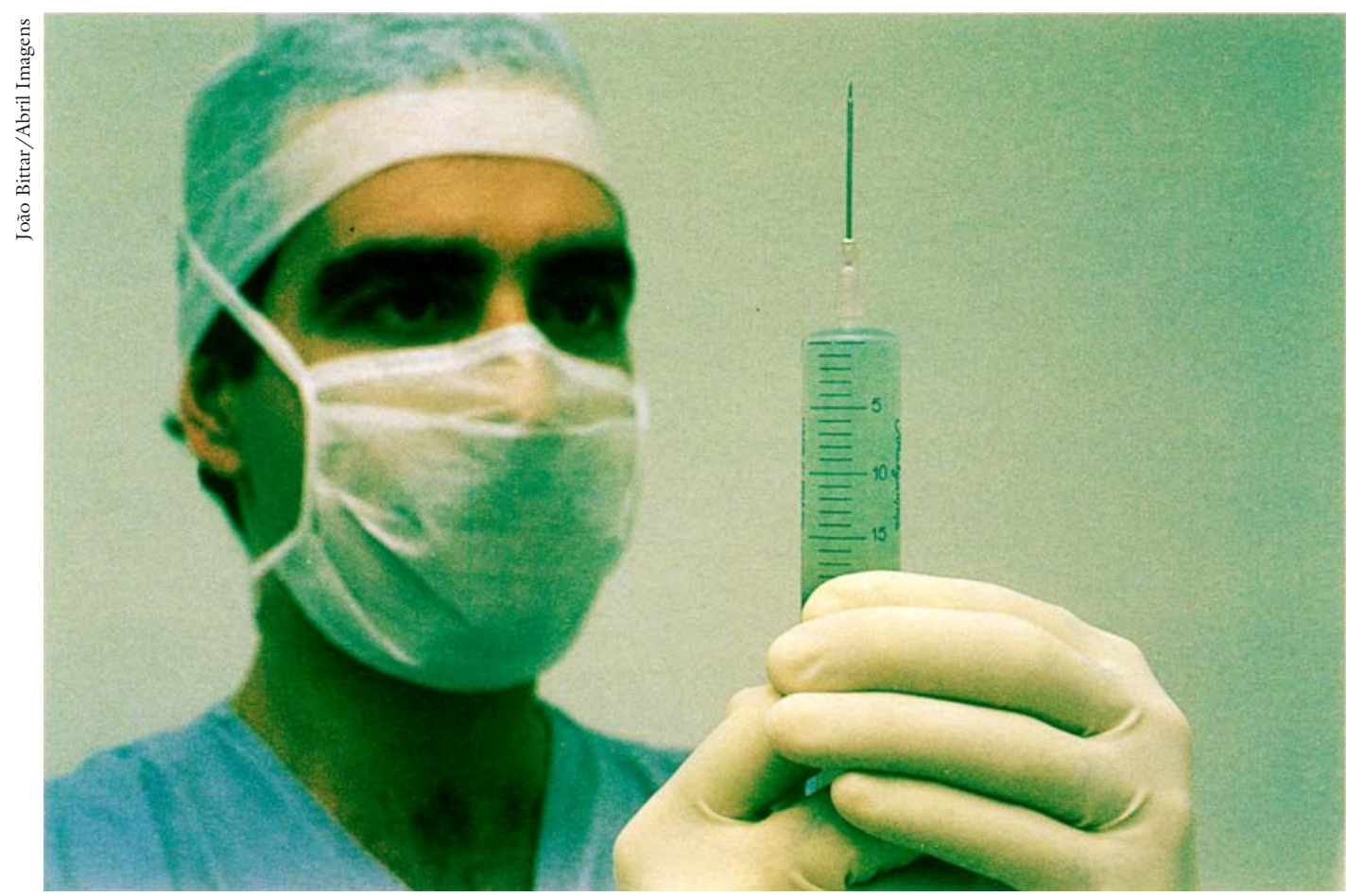

Médico-anestesista da Santa Casa, SP

\section{Exigências de um modelo federativo}

Ao transferir para os municípios a sua rede ambulatorial e parte da rede hospitalar, alguns estados abandonaram seu papel de prestador de serviços, mas não se capacitaram para assumir suas novas atribuições. $\mathrm{O}$ processo de descentralização instaurado pelo SUS, centrado na relação União-municípios, deixou à margem os estados como instâncias de planejamento, financiamento, avaliação e controle. Com isso, permaneceram na disputa pelo papel de prestador, com o SUS deixando de dispor de uma instância articuladora e otimizadora dos recursos disponíveis em cada município, atravancando assim a possibilidade de se programar e de operar redes de serviços de âmbito regional.

Sem essa instância de integração e de desenvolvimento regional, que deveria ser típica num modelo exemplar de Estado federativo, os municípios, considerados isoladamente, reforçam seu papel mas também as desigualdades entre si. Os que estão melhor aparelhados prestam melhores serviços à população local, mas acabam decaindo em qualidade pelo aumento da demanda das populações vizinhas. É um círculo vicioso que acentua as distorções regionais e que acaba desequilibrando a redistribuição dos re- 
cursos destinados à saúde. Daí a importância de se ter, nas secretarias estaduais de saúde, uma parceria indispensável para a adequada gestão do SUS. Mesmo que deixe de lado seu papel de prestador de serviços assistenciais, a unidade federativa é insubstituível na regulação da gestão de suas respectivas regiões, planejando, articulando e reordenando os recursos disponíveis e/ou exigidos por cada uma delas. A partir dessa atuação é que os estados disporão de meios para, entre outras atenções, voltar-se para a vigilância sanitária e epidemiológica de seu próprio território físico.

\section{Os muitos desafios}

Transferir competências, no caso da saúde, não pode ser visto como uma emulação do pragmatismo que impera na gestão privada, explicado pela busca do lucro, seu motor principal, mas pela busca da eficiência nos gastos do dinheiro público, tendo como contrapartida a exigência da responsabilidade fiscal dos agentes que o disponibilizam e, como função primordial, o atendimento correto das demandas da população.

Essas exigências se ligam à mudança de hábitos, à introdução de uma cultura centrada na cidadania e na construção de anteparos jurídicos que a garantam. Dessa forma, não apenas os municípios, os estados, a União, os sindicatos, as associações e, sobretudo os cidadãos, são convocados à participação. As pessoas não moram na União ou no estado, mas no município. Essa é a lógica da descentralização do SUS. Atualmente, 90,85\% dos municípios brasileiros já assumiram essa lógica, com $89,5 \%$ da população do país cobertos pelo sistema.

Uma pesquisa encomendada pelo Ministério da Saúde ao Instituto de Saúde da Secretaria de Estado da Saúde de São Paulo, abrangendo 12 municípios localizados em sete diferentes estados da União, todos eles habilitados em gestão semiplena, em 1994, mostrou resultados bastante animadores. Houve um aumento de funcionários atuando no setor saúde e um incremento nos gastos totais per capita, embora os recursos tenham provindo basicamente dos cofres da União. Ou seja, naqueles 12 municípios

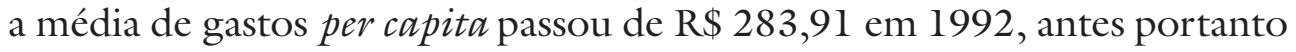
da municipalização, para R\$ 435,50 em 1996.

Com respeito às internações hospitalares, houve uma redução significativa entre 1994 e 1996, com uma queda de 26,85\% para cada 100 habitantes em 10 dos 12 municípios pesquisados. A redução, certamente, deveu-se a obediência às normas emanadas do gestor federal, mas não teria sido alcançada sem a participação e a fiscalização do gestor municipal que, para tanto, ampliou a oferta dos serviços ambulatoriais. Outras variáveis, 
também reveladas pela pesquisa do Instituto de Saúde de São Paulo naqueles 12 municípios, mostraram igualmente uma queda na cesariana com relação ao parto normal e ampliação da cobertura vacinal.

A batalha do Ministério da Saúde para a habilitação dos 504 municípios que ainda não aderiram ao sistema está prestes a terminar. Mas não se pode dizer o mesmo em relação às unidades federativas, cuja maioria ainda precisa ser conquistada.

Como conclusão, ter a medida exata, neste ainda curto espaço de vigência do SUS, sobre os impactos que a municipalização da saúde provocou, ou pode provocar, para a melhoria das condições sanitárias da nossa população, só o tempo dirá. Os primeiros indicadores são extremamente favoráveis. Mas por tratar-se de um ideal generoso, é extremamente oneroso: tanto na viabilização dos recursos financeiros, quanto no recrutamento e engajamento dos recursos humanos.

João Yunes é médico sanitarista, professor da Faculdade de Saúde Pública da USP, ex-representante do Brasil na Organização Panamericana de Saúde e atual titular da Secretaria de Políticas de Saúde do Ministério da Saúde. 